\title{
Successful treatment of a patient with congenital kyphoscoliosis associated with tethered cord
}

\author{
Hui-Ren Tao, MD, ${ }^{1}$ Tian-Li Yang, MD, ${ }^{1}$ Michael S. Chang, MD, ${ }^{2}$ Huan Li, MD, ${ }^{3}$ Da-Wei Zhang, MD, ${ }^{1}$ \\ Hong-Bin Fan, MD, ${ }^{1}$ Chao Shen, MD, ${ }^{1}$ and Zhuo-Jing Luo, MD'
}

\begin{abstract}
1Department of Orthopedics and 3Department of Cardiology, Xijing Hospital, Fourth Military Medical University, Xi'an, China; and the ${ }^{2}$ Adult and Pediatric Spine Surgery, Sonoran Spine Center, Mesa, Arizona
\end{abstract}

\begin{abstract}
Tethered cord is a common finding in congenital scoliosis. The most frequently advocated approach for this condition is to perform prophylactic detethering of the cord before scoliosis corrective surgery. The authors report on a 14-year-old patient with congenital thoracic kyphoscoliosis associated with a tethered cord, who developed progressive paraparesis and was successfully treated by posterior spine shortening osteotomy alone without prophylactic untethering. The patient had a $103^{\circ}$ scoliotic curve together with a $93^{\circ}$ kyphotic curve with an apical vertebra of T-7. Furthermore, he developed a significant progression of neurological deficits, including weakness of both legs and urinary and bowel incontinence. Preoperative MRI revealed that the spinal cord was entrapped by the apical vertebra and the low-placed conus medullaris was at approximately L-5. A posterior vertebral column resection of T-7 was performed for the purpose of simultaneously correcting the kyphoscoliosis and releasing tension on the tethered cord without a true detethering surgery. The patient's spinal cord function recovered completely from Frankel $D$ to Frankel $E$ by 6 months after the procedure. Evaluation at 31 months after surgery showed maintenance of good curve correction and normal neurological function.
\end{abstract}

http://thejns.org/doi/abs/10.3171/2014.9.SPINE13528

KEY WORDS kyphoscoliosis; tethered cord; spinal osteotomy; neurological deficit; surgical technique

$\mathrm{C}$ ONGENITAL scoliosis is often associated with intraspinal anomalies such as Chiari deformity, spinal cord malformation, tethered cord, and the like. ${ }^{2,25,31}$ Classically, tethered cord syndrome refers to a constellation of neurological signs and symptoms resulting from longitudinal traction on the caudal end of the spinal cord. A conus medullaris located below the level of L1-2 and/or the presence of a thickened filum terminale are the typical radiological diagnostic criteria. ${ }^{4,17,31}$ Surgical detethering is consistently reported to be effective in treating symptomatic tethered cord syndrome..$^{3,5,15,30}$ However, complications such as cerebrospinal fluid leakage and neurological deterioration are also common..$^{1928}$ To minimize these complications, Kokubun pioneered an alternative surgical procedure for the treatment of tethered cord syndrome via spine-shortening vertebral osteotomy. ${ }^{13}$ This procedure has the distinct advantage of reducing neural tension indirectly without violating the dura. There have been several reports of the favorable results achieved by the use of this procedure in patients with symptomatic tethered cord. $8,9,11,12,15,21$

Spine-shortening vertebral osteotomy has also been described in the literature as an effective approach to correct severe kyphoscoliosis. ${ }^{16,22,29}$ Therefore, we hypothesized that a spine-shortening vertebral osteotomy alone could simultaneously treat both kyphoscoliosis and an associated tethered cord without necessitating a detethering procedure. We are unaware of any study in the literature that addresses the utility of spine-shortening vertebral osteotomy for both of these purposes concurrently, especially in patients with neurological deficits. In this case report, we present a patient with congenital kyphoscoliosis associated with tethered cord. The patient developed progressive paraparesis and underwent posterior vertebral column resection (PVCR) for the purpose of simultaneously correcting the kyphoscoliosis and releasing tension on the tethered cord without a true detethering surgery. He made a complete neurological recovery by 6 months

ABBREVIATIONS PVCR = posterior vertebral column resection; SSEP = somatosensory evoked potential.

SUBMITTED June 2, 2013. ACCEPTED September 15, 2014.

INCLUDE WHEN CITING Published online October 24, 2014; DOI: 10.3171/2014.9.SPINE13528.

DISCLOSURE The authors report no conflict of interest concerning the materials or methods used in this study or the findings specified in this paper. This work was supported by National Natural Science Fund Projects of China (Grant No. 81070698) and Xijing Hospital Grant for Developing New Clinical Technique (Grant No. XJZT10Y07). 
after the procedure, maintaining curve correction and normal neurological function at 31 months' follow-up.

\section{Case Report}

History and Presentation

This 14-year-old boy presented to Xijing Hospital with a 6-month history of progressive weakness in both lower extremities. He had a normal gestation and development with the exception of a small hump on his back at his birth without any other abnormal skin signs such as hairy patches, dermal sinus tracts, or skin appendages. At the age of 3, he was first formally diagnosed with scoliosis and was treated by brace therapy at an outside institution. The brace therapy was not effective in halting the curve progression and was discontinued when the patient was 5 years old. The patient continued to have worsening progression of the curve until presentation at 14 years of age. At his initial presentation to us, the right lower extremity was subjectively weaker than the left. He also was prone to falling when running or jumping. He had no back pain and denied any bladder or bowel dysfunction. On physical examination, he walked unaided but with faltering steps. A prominent hump was seen in the thoracic spine; there were no abnormal cutaneous manifestations. He had no apparent lower-extremity visible abnormalities such as atrophy of the leg or foot. He had global lower-extremity weakness with $4 / 5$ strength on the right and $4+5$ on the left. Deep tendon reflexes were slightly increased and the Babinski sign was present bilaterally. No significant sensory loss was detected over the affected areas including the perineum. Long-cassette standing radiographs showed that he had a thoracic kyphoscoliosis with a $103^{\circ}$ scoliotic curve together with a $93^{\circ}$ kyphotic curve with an apical vertebra of T-7 resulting from an unsegmented wedge-shaped vertebra from the T-6 to the T-8 level (Fig. 1). Both curves showed minimal flexibility on dynamic radiographs. The preoperative MRI study revealed that the spinal cord was entrapped by the apical vertebra and the low-placed conus medullaris was at approximately L-5 (Figs. 2 and 3). The family refused surgical intervention initially, and the patient came back 2 months later with significant progression of his neurological deficit. At this time he was not able to walk independently (Video 1) and had difficulty in raising his right ankle.

VIDEO 1. Clip from preoperative video showing that the patient had significant lower-extremity weakness and walked slowly and unsteadily with support. Copyright Hui-Ren Tao. Published with permission. Click here to view with Media Player. Click here to view with Quicktime.

He also developed urinary and bowel incontinence. Repeat neurological examination revealed significant decrease in muscle power of both legs: tibialis anterior and the extensor hallucis longus were $3-/ 5$ and the power of all the other muscles was $3 / 5$ to $4^{-/} / 5$. The sensation over the perineal region was also partially lost, but the cremasteric reflex was normal. The overall spinal cord function was classified as Frankel D. The family no longer hesitated to accept the operation at this point.

\section{Operation}

A posterior vertebral column shortening osteotomy of
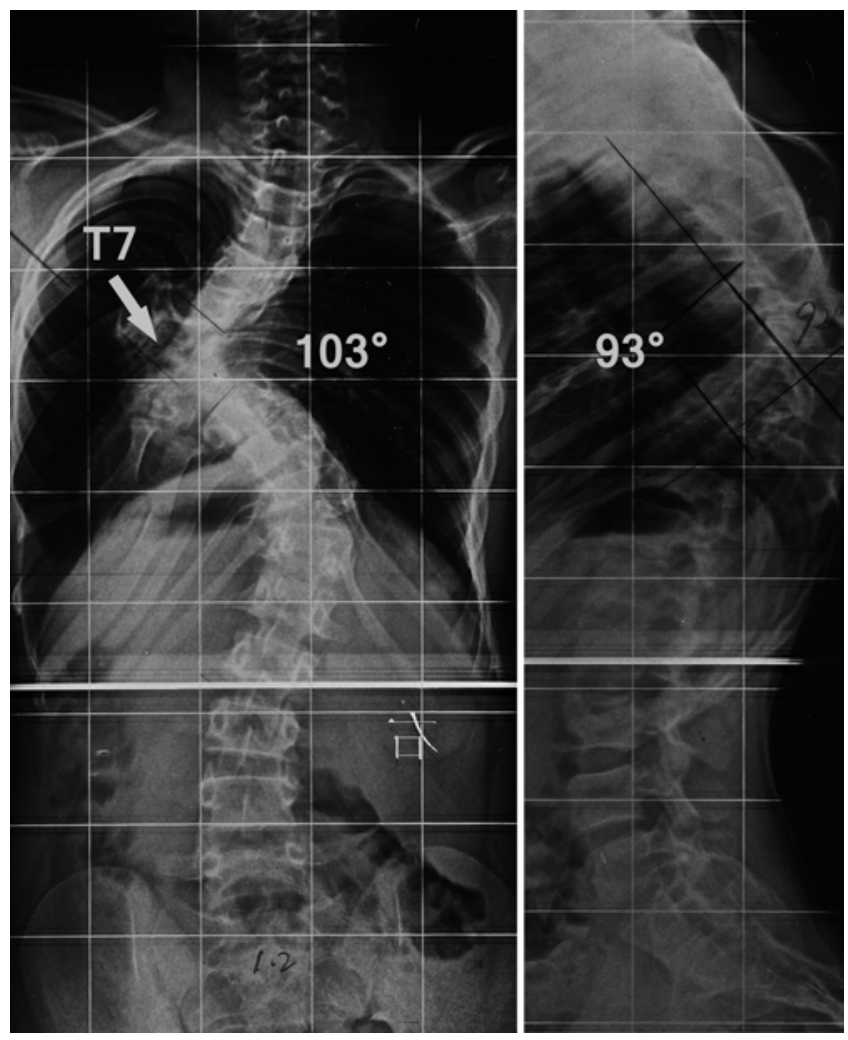

FIG. 1. Preoperative anteroposterior (left) and lateral (right) standing scoliosis radiographs.

T-7 was planned to simultaneously relieve the compression of the spinal cord and decrease the tension on the cord, as well as correct the kyphoscoliosis. Because monitoring of motor evoked potentials was not available when the surgery was done in 2007, somatosensory evoked potential (SSEP) monitoring was performed in conjunction with multiple wake-up tests. A long midline posterior incision from T-1 to L-2 was made and we found that the vertebrae from T- 6 to T- 8 were fused together. Pedicle screws were placed at T-2, T-5, T-9, L-1, and L-2 on the left side and T-2, T-3, T-4, T-5, T-9, L-1, and L-2 on the right side by free-hand technique. Posterior vertebral column resection was performed at the T-7 vertebra. After removing the processes and laminae from T-6 to T-8, a total facetectomy from T-6 to T-8 was performed. The proximal portion of the seventh rib was removed bilaterally. The lateral wall of the fused T6-8 vertebral bodies was then dissected subperiosteally. After placement of a temporary rod, vertebral column resection was carried out at T-7 by decancellation of the vertebral body using a combination of curette, pituitary rongeur, and highspeed bur. After the osteotomy was finished, there was a 3 -cm gap between the osteotomy surfaces. A compressive force was then imposed through the temporary rod on the convex side, while a mild distraction was effected on the concave side to close the osteotomy site while correcting the deformity. The temporary rod was then replaced by a contoured permanent rod on the convex side before placement of the definitive concave rod. Local bone grafting was performed using bone chips from resected ribs and 

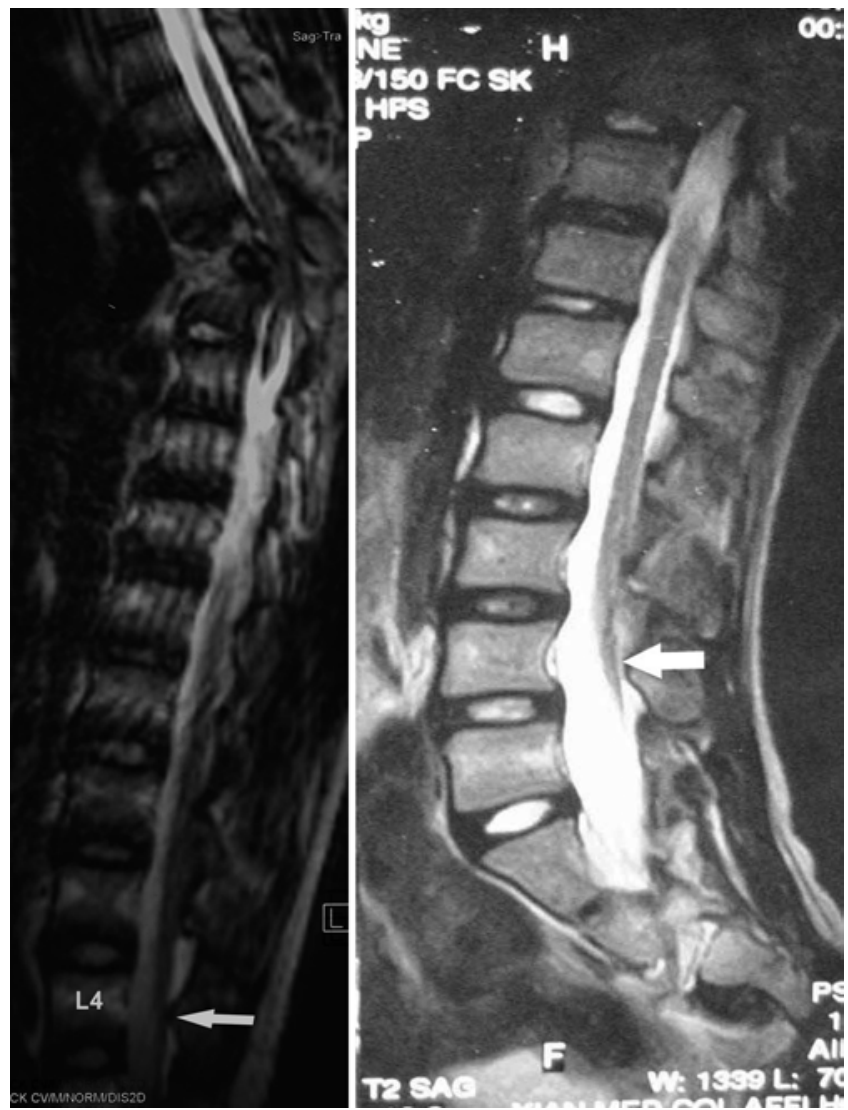

FIG. 2. Preoperative sagittal T2-weighted MR images showing the apical spinal cord entrapment by T-7 and the low-placed conus medullaris that was at the level of $L 4 / 5$.
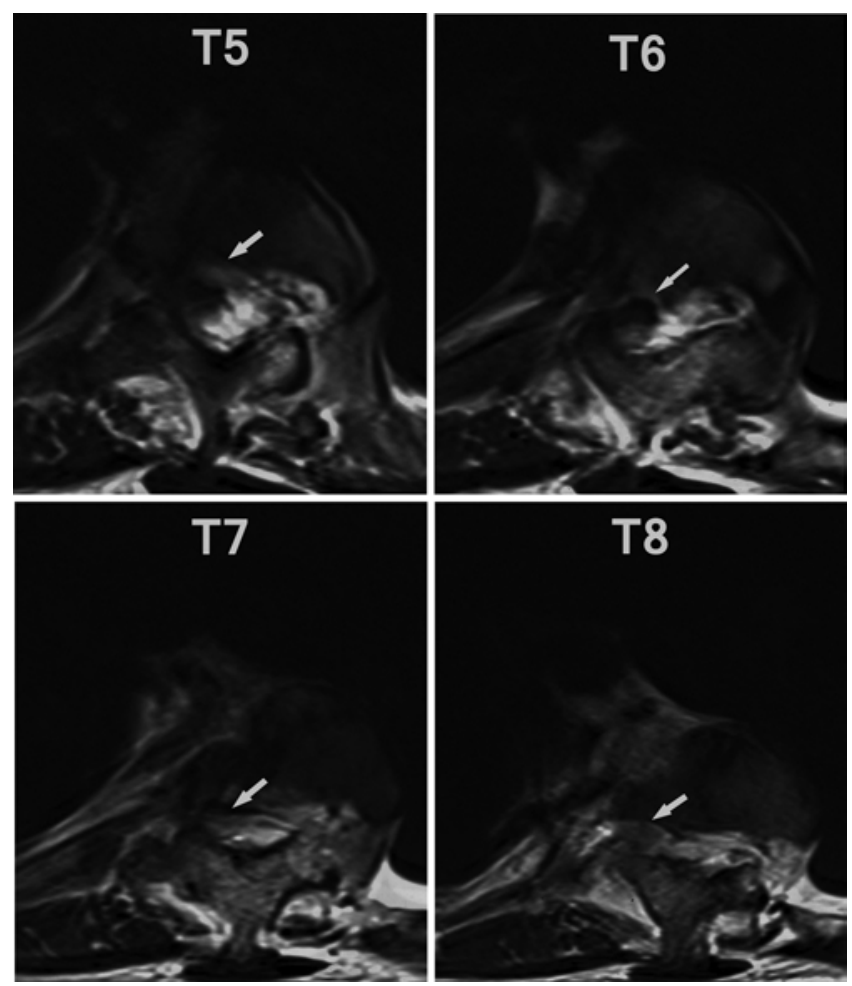

FIG. 3. Preoperative axial T2-weighted MR images showing the distortion of the cord (arrows) at the apex of the kyphotic curve. vertebrae. No abnormalities in SSEPs were noticed and all the wake-up tests were unremarkable. The total surgical time was 8 hours, and the blood loss was $2700 \mathrm{ml}$.

\section{Postoperative Course}

The patient's postoperative course was uneventful. He recovered independent walking ability as well as bladder and bowel function in 2 months. At 6 months after the operation, he had regained full muscle strength in his lower extremities and no longer had difficulty in walking, running, or jumping (Video 2).

VIDEO 2. Clip from video obtained 6 months postoperatively showing that the patient had regained full muscle strength in his lower extremities and no longer had difficulty walking. Copyright Hui-Ren Tao. Published with permission. Click here to view with Media Player. Click here to view with Quicktime.

At 31 months' follow-up, he still had good neurological function without any complaint. His spinal cord function improved from Frankel D to Frankel E postoperatively. The postoperative radiographs showed that the scoliosis was corrected to $67^{\circ}$ (correction rate, 54.4\%) and the local kyphosis was corrected to $35^{\circ}$ (correction rate, $62.4 \%$ ) (Fig. 4). Postoperative MRI showed complete relief of apical spinal cord entrapment (Figs. 5 and 6), but the co-

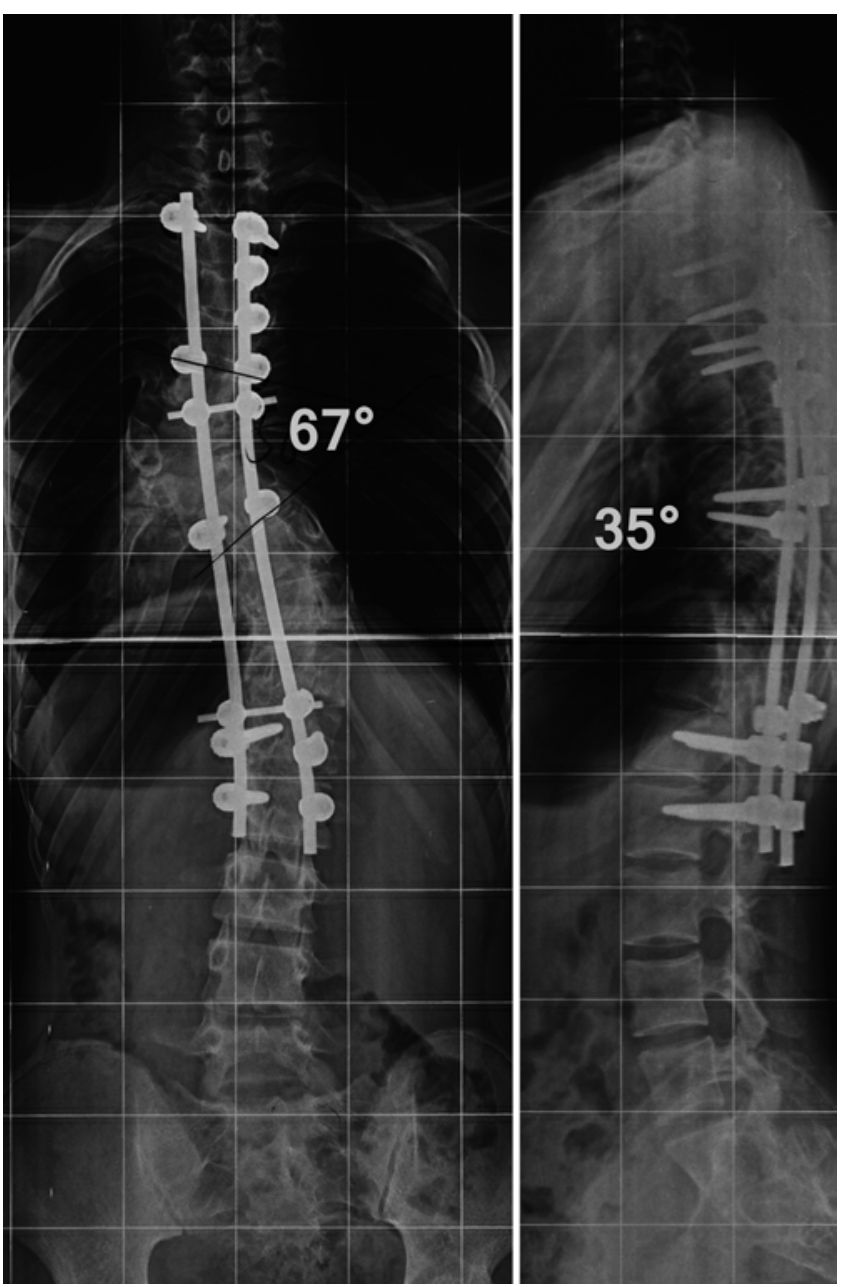

FIG. 4. Postoperative anteroposteror (left) and lateral (right) standing scoliosis radiographs. 
nus medullaris was still as low as before surgery (Fig. $5)$. Good curve correction and trunk balance were still evident at 31 months' follow-up (Fig. 7).

\section{Discussion}

It is controversial whether there is a need for preventive detethering in the treatment of kyphoscoliosis associated with tethered cord syndrome. Some surgeons consider it unnecessary to detether the cord before patients develop symptoms. ${ }^{18,27}$ However, other surgeons believe that the spinal cord will be put at high risk for injury when subjected to excessive stretching during surgical correction of spinal deformity without prior detethering. As a result, they recommend that a detethering procedure be performed followed by deformity correction 3-6 months later. ${ }^{1}$ Despite some success with this 2-stage strategy, it has inherent disadvantages, such as additional trauma, more medical cost, and additional anesthetic exposure. Furthermore, retethering might occur 3-6 months later. ${ }^{23,24,32}$ Therefore, some authors advocate performing spinal cord detethering and deformity correction in one stage.,20,26 Whether it is performed separately or as part of a single-stage operation, detethering does entail some risk of complications such as deterioration of neurological function and wound problems as well as incomplete detethering or retethering. ${ }^{27}$ Matsumoto et al. reported on a patient who had progressive kyphoscoliosis associated with tethered cord and underwent 2-stage corrective surgery. Unfortunately, the patient developed worsening neurological deficits after the untethering procedure, including paresthetic pain in the lower extremities and bladder and bowel dysfunction. ${ }^{19}$

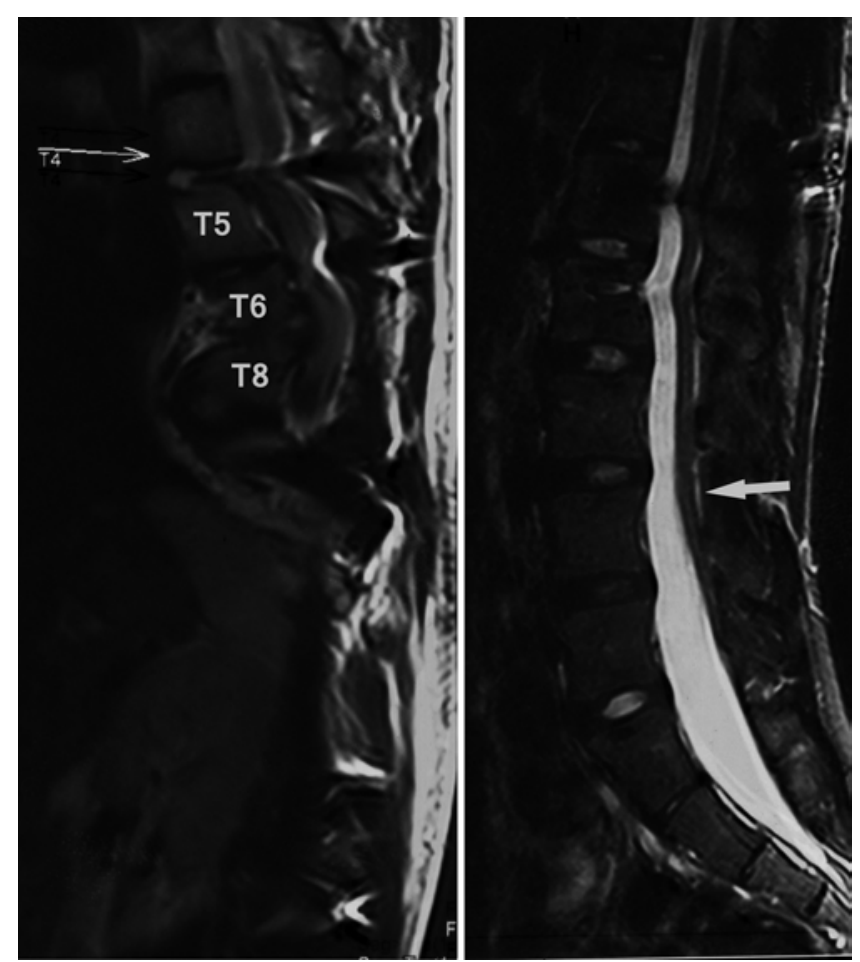

FIG. 5. Postoperative sagittal T2-weighted MR images showing complete relief of apical spinal cord entrapment, with the conus medullaris (arrow) still as low as preoperatively.
The rationale behind performing detethering with the use of spine-shortening osteotomy is to reduce neural tension of the spinal cord via an indirect approach. ${ }^{13,14}$ In a cadaver model, Grande et al. found that a shortening vertebral column substraction osteotomy at the thoracolumbar junction significantly reduced neural tension. ${ }^{6}$ There have also been several reports that show the successful treatment of tethered cord syndrome by spine-shortening osteotomy. $8,9,11,12,21$

Spine-shortening osteotomy is a technically demanding procedure which has also been shown to effectively correct fixed kyphosis or kyphoscoliosis. ${ }^{16,19}$ Jalanko et

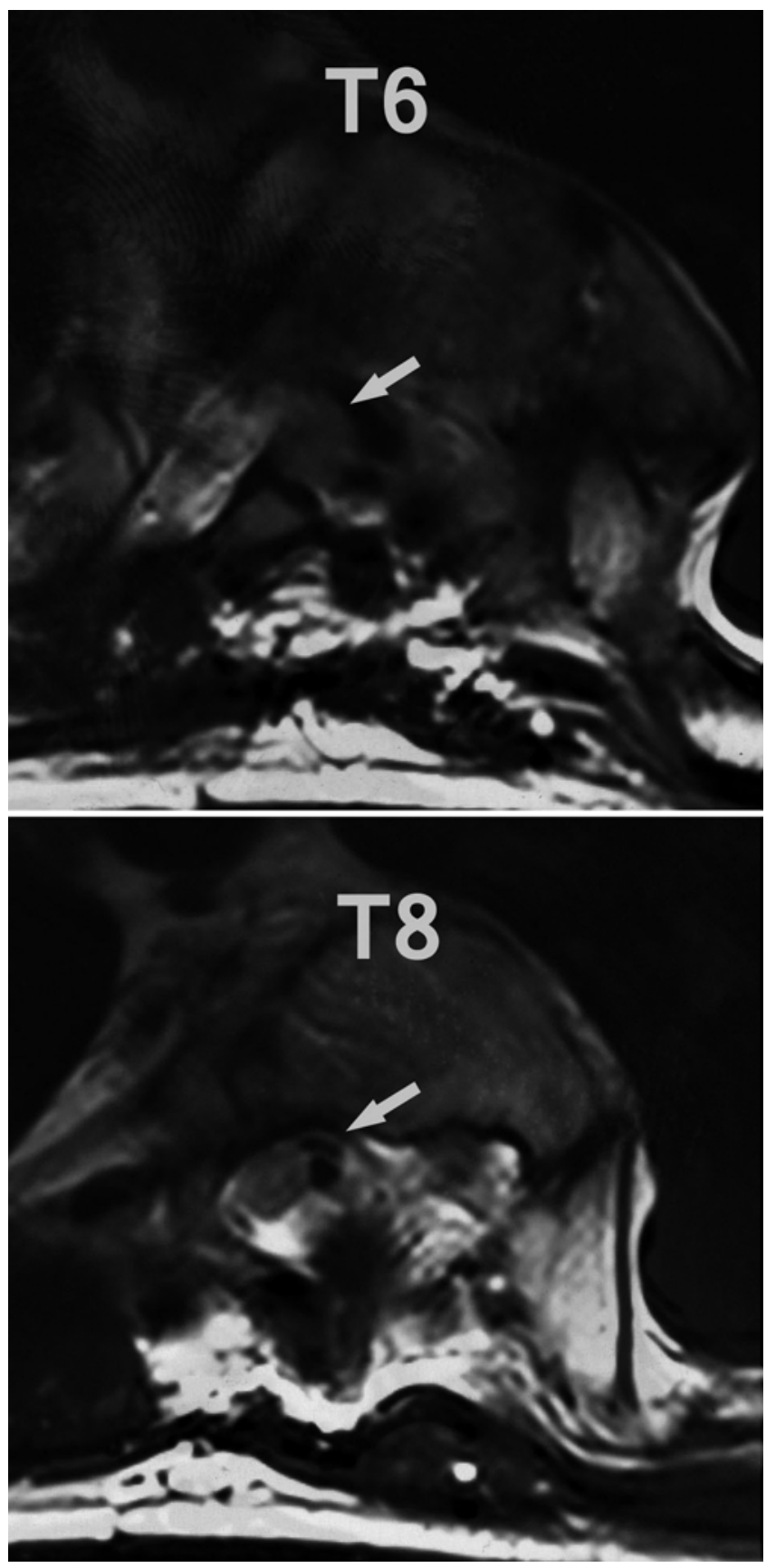

FIG. 6. Postoperative axial T2-weighted MR images showing complete relief of apical spinal cord compression (arrows). 


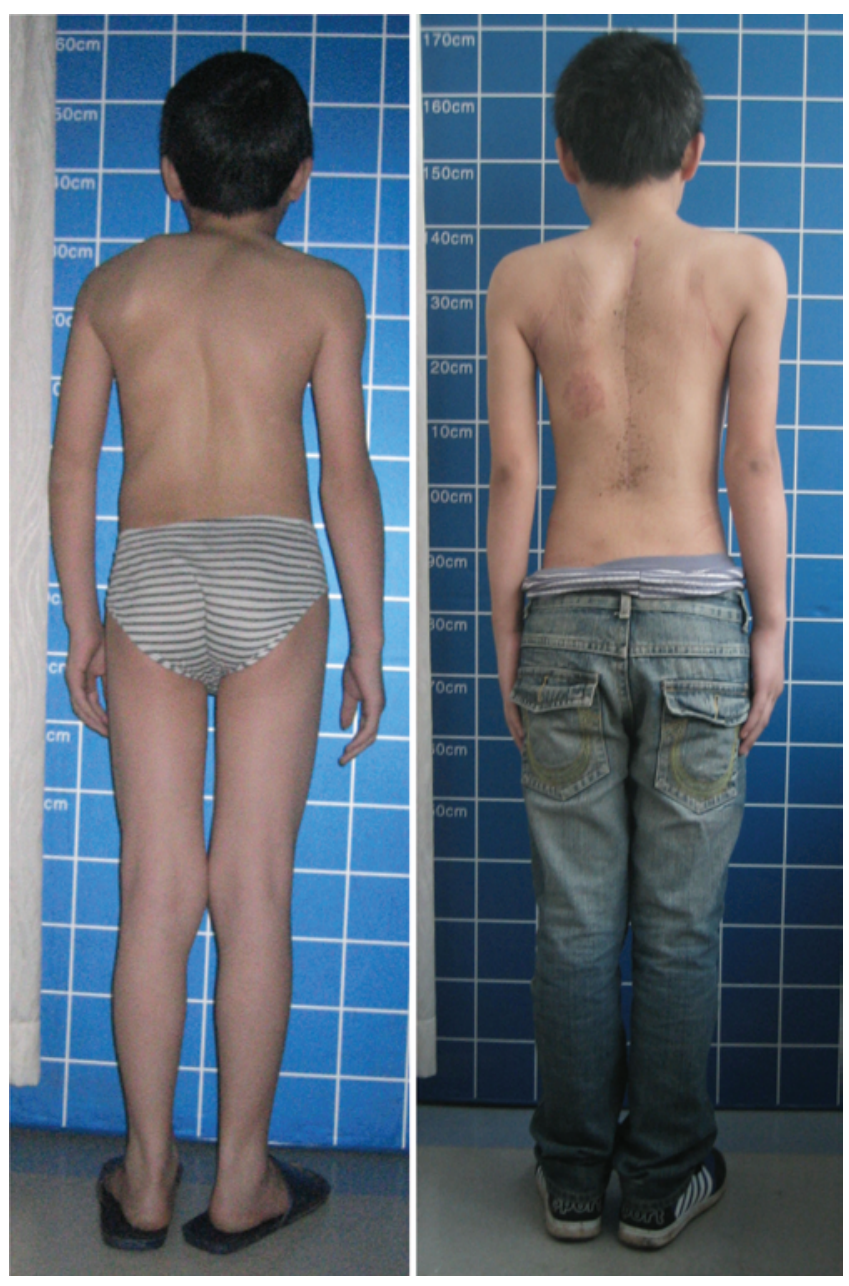

FIG. 7. Preoperative and postoperative photographs demonstrating the patient's clinical improvement. Figure is available in color online only.

al. reported that the use of hemivertebrectomy alone in the thoracolumbar/lumbar region led to neurological recovery in 4 patients. ${ }^{10}$ But, there were no reports about the successful simultaneous treatment of tethered cord and scoliosis by single-stage posterior thoracic vertebral column resection. We have employed the principle of shortening the spine to simultaneously untether a cord and correct scoliosis since 2006. Regarding this case, entrapment of the spinal cord at the apical vertebra was the main cause of the patient's progressive paraparesis. Tethering increased the tension of the spinal cord and exacerbated the neural deficit. Surgical planning should be focused on relieving both the entrapment and tethering of the spinal cord. In this report, posterior vertebral column resection (PVCR) only, without any detethering procedure, was chosen and proved to be very effective in providing good correction of the curve while simultaneously restoring the function of the spinal cord owing to its indirect detethering effect. To our knowledge, this is the first case report in the literature to elucidate that PVCR alone is an effective procedure to combine untethering and corrective surgery while treating kyphoscoliosis associated with a tethered cord, even in the setting of significant neurological dysfunction.

\section{References}

1. Acaroğlu E, Alanay A, Akalan N, Atilla B, Bulutçu E, Surat A: Risk factors associated with corrective surgery in congenital scoliosis with tethered cord. Turk J Pediatr 39:373-378, 1997

2. Belmont PJ Jr, Kuklo TR, Taylor KF, Freedman BA, Prahinski JR, Kruse RW: Intraspinal anomalies associated with isolated congenital hemivertebra: the role of routine magnetic resonance imaging. J Bone Joint Surg Am 86-A:1704-1710, 2004

3. Bowman RM, Mohan A, Ito J, Seibly JM, McLone DG: Tethered cord release: a long-term study in 114 patients. Clinical article. J Neurosurg Pediatr 3:181-187, 2009

4. Bui CJ, Tubbs RS, Oakes WJ: Tethered cord syndrome in children: a review. Neurosurg Focus 23(2):E2, 2007

5. Chern JJ, Dauser RC, Whitehead WE, Curry DJ, Luerssen TG, Jea A: The effect of tethered cord release on coronal spinal balance in tight filum terminale. Spine (Phila Pa 1976) 36:E944-E949, 2011

6. Grande AW, Maher PC, Morgan CJ, Choutka O, Ling BC, Raderstorf TC, et al: Vertebral column subtraction osteotomy for recurrent tethered cord syndrome in adults: a cadaveric study. J Neurosurg Spine 4:478-484, 2006

7. Hamzaoglu A, Ozturk C, Tezer M, Aydogan M, Sarier M, Talu U: Simultaneous surgical treatment in congenital scoliosis and/or kyphosis associated with intraspinal abnormalities. Spine (Phila Pa 1976) 32:2880-2884, 2007

8. Hsieh PC, Ondra SL, Grande AW, O'Shaughnessy BA, Bierbrauer K, Crone KR, et al: Posterior vertebral column subtraction osteotomy: a novel surgical approach for the treatment of multiple recurrences of tethered cord syndrome. Technical note. J Neurosurg Spine 10:278-286, 2009

9. Hsieh PC, Stapleton CJ, Moldavskiy P, Koski TR, Ondra SL, Gokaslan ZL, et al: Posterior vertebral column subtraction osteotomy for the treatment of tethered cord syndrome: review of the literature and clinical outcomes of all cases reported to date. Neurosurg Focus 29(1):E6, 2010

10. Jalanko T, Rintala R, Puisto V, Helenius I: Hemivertebra resection for congenital scoliosis in young children: comparison of clinical, radiographic, and health-related quality of life outcomes between the anteroposterior and posterolateral approaches. Spine (Phila Pa 1976) 36:41-49, 2011

11. Kanno H, Aizawa T, Ozawa H, Hoshikawa T, Itoi E, Kokubun S: Spine-shortening vertebral osteotomy in a patient with tethered cord syndrome and a vertebral fracture. Case report. J Neurosurg Spine 9:62-66, 2008

12. Kawamura I, Ishido Y, Zenmyo M, Yamamoto T, Kagawa Y, Komiya S, et al: Pedicle subtraction osteotomy for adult tethered cord syndrome with lumbar canal stenosis: report of two cases. Int J Neurosci 120:735-737, 2010

13. Kokubun S: [Shortening spinal osteotomy for tethered cord syndrome in adults.] Spine Spinal Cord 8 (Suppl 12):5, 1995 (Jpn)

14. Kokubun S, Ozawa H, Aizawa T, Ly NM, Tanaka Y: Spineshortening osteotomy for patients with tethered cord syndrome caused by lipomyelomeningocele. Clinical article. J Neurosurg Spine 15:21-27, 2011

15. Kuntz C IV, Park TS: Introduction. Tethered cord. Neurosurg Focus 29(1):Introduction, 2010

16. Lenke LG, O’Leary PT, Bridwell KH, Sides BA, Koester LA, Blanke KM: Posterior vertebral column resection for severe pediatric deformity: minimum two-year follow-up of thirty-five consecutive patients. Spine (Phila Pa 1976) 34:2213-2221, 2009

17. Lew SM, Kothbauer KF: Tethered cord syndrome: an updated review. Pediatr Neurosurg 43:236-248, 2007

18. Liu JM, Shen JX, Zhang JG, Zhao H, Zhao Y, Li SG, et al: [The surgery treatment of scoliosis associated with tethered 
cord.] Zhonghua Wai Ke Za Zhi 50:333-337, 2012 (Chinese)

19. Matsumoto M, Watanabe K, Tsuji T, Ishii K, Takaishi H, Nakamura M, et al: Progressive kyphoscoliosis associated with tethered cord treated by posterior vertebral column resection: a case report. Spine (Phila Pa 1976) 34:E965-E968, 2009

20. Mehta VA, Gottfried ON, McGirt MJ, Gokaslan ZL, Ahn ES, Jallo GI: Safety and efficacy of concurrent pediatric spinal cord untethering and deformity correction. J Spinal Disord Tech 24:401-405, 2011

21. Miyakoshi N, Abe E, Suzuki T, Kido T, Chiba M, Shimada Y: Spine-shortening vertebral osteotomy for tethered cord syndrome: report of three cases. Spine (Phila Pa 1976) 34:E823-E825, 2009

22. O’Shaughnessy BA, Kuklo TR, Hsieh PC, Yang BP, Koski TR, Ondra SL: Thoracic pedicle subtraction osteotomy for fixed sagittal spinal deformity. Spine (Phila Pa 1976) 34:2893-2899, 2009

23. Ogiwara H, Lyszczarz A, Alden TD, Bowman RM, McLone DG, Tomita T: Retethering of transected fatty filum terminales. Clinical article. J Neurosurg Pediatr 7:42-46, 2011

24. Ostling LR, Bierbrauer KS, Kuntz C IV: Outcome, reoperation, and complications in 99 consecutive children operated for tight or fatty filum. World Neurosurg 77:187-191, 2012

25. Prahinski JR, Polly DW Jr, McHale KA, Ellenbogen RG: Occult intraspinal anomalies in congenital scoliosis. J Pediatr Orthop 20:59-63, 2000

26. Samdani AF, Asghar J, Pahys J, D’Andrea L, Betz RR: Concurrent spinal cord untethering and scoliosis correction: case report. Spine (Phila Pa 1976) 32:E832-E836, 2007

27. Samdani AF, Fine AL, Sagoo SS, Shah SC, Cahill PJ, Clements DH, et al: A patient with myelomeningocele: is untethering necessary prior to scoliosis correction? Neurosurg Focus 29(1):E8, 2010

28. Solmaz I, Izci Y, Albayrak B, Cetinalp E, Kural C, Sengul G, et al: Tethered cord syndrome in childhood: special emphasis on the surgical technique and review of the literature with our experience. Turk Neurosurg 21:516-521, 2011

29. Suk SI, Chung ER, Kim JH, Kim SS, Lee JS, Choi WK: Posterior vertebral column resection for severe rigid scoliosis. Spine (Phila Pa 1976) 30:1682-1687, 2005
30. Tubbs RS, Oakes WJ, Heimburger RF: The relationship of the spinal cord to scoliosis. J Neurosurg (2 Suppl) 101:228233, 2004

31. Warder DE: Tethered cord syndrome and occult spinal dysraphism. Neurosurg Focus 10(1):E1, 2001

32. Yong RL, Habrock-Bach T, Vaughan M, Kestle JR, Steinbok P: Symptomatic retethering of the spinal cord after section of a tight filum terminale. Neurosurgery 68:1594-1602, 2011

\section{Author Contributions}

Conception and design: Tao. Acquisition of data: Tao, Shen. Analysis and interpretation of data: Tao. Drafting the article: Tao, Yang, Fan, Zhang. Critically revising the article: all authors. Reviewed submitted version of manuscript: all authors. Approved the final version of the manuscript on behalf of all authors: Tao. Administrative/technical/material support: Tao. Study supervision: Tao, Luo.

\section{Supplemental Information \\ Videos}

Video 1, Media Player. http://mfile.akamai.com/21490/wmv/ digitalwbc.download.akamai.com/21492/wm.digitalsource-naregional/spine13-528_video_1a.asx.

Video 1, Quicktime. http://mfile.akamai.com/21488/mov/ digitalwbc.download.akamai.com/21492/qt.digitalsource-global/ spine13-528_video_1a.mov.

Video 2, Media Player. http://mfile.akamai.com/21490/wmv/ digitalwbc.download.akamai.com/21492/wm.digitalsource-naregional/spine13-528_video_2a.asx.

Video 2, Quicktime. http://mfile.akamai.com/21488/mov/ digitalwbc.download.akamai.com/21492/qt.digitalsource-global/ spine13-528_video_2a.mov.

\section{Correspondence}

Hui-Ren Tao, Department of Orthopedics, Xijing Hospital, Fourth Military Medical University, 15 West Changle Rd., Xi'an 710032, China.email: taohr816@fmmu.edu.cn. 